\section{UJMM

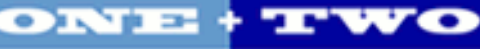

Volume 2 | 2009 Fall

\section{Undergraduate Journal of Mathematical}

Modeling: One + Two

2009

\title{
Modulus of Subgrade Reaction and Deflection
}

Austin Potts

University of South Florida

Advisors:

Arcadii Grinshpan, Mathematics and Statistics

Rajan Sen, Civil \& Enviromental Engineering

Problem Suggested By: Rajan Sen

Follow this and additional works at: https://digitalcommons.usf.edu/ujmm

Part of the Mathematics Commons

UJMM is an open access journal, free to authors and readers, and relies on your support:

Donate Now

\section{Recommended Citation}

Potts, Austin (2009) "Modulus of Subgrade Reaction and Deflection," Undergraduate Journal of Mathematical Modeling: One + Two: Vol. 2: Iss. 1, Article 5.

DOI: http://dx.doi.org/10.5038/2326-3652.2.1.5

Available at: https://digitalcommons.usf.edu/ujmm/vol2/iss1/5 


\title{
Modulus of Subgrade Reaction and Deflection
}

\begin{abstract}
Differential equations govern the bending and deflection of roads under a concentrated load. Identifying critical parameters, such as the maximum deflection and maximum bending moments of a street supported by an elastic subgrade, is key to designing safe and reliable roadways. This project solves the underlying differential equation in pavement deflection and tests various parameters to highlight the importance in selecting proper foundation materials.
\end{abstract}

Keywords

Materials, Road Construction, Deflection, Subgrade Reaction

Creative Commons License

(c) (i) () $\Theta$

This work is licensed under a Creative Commons Attribution-Noncommercial-Share Alike 4.0 License. 


\section{TABLE OF CONTENTS}

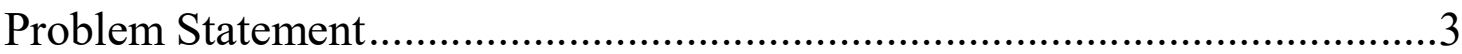

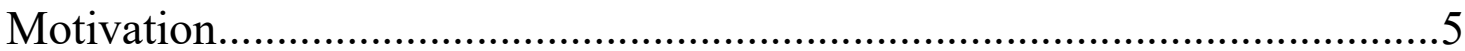

Mathematical Description and Solution Approach .......................................5

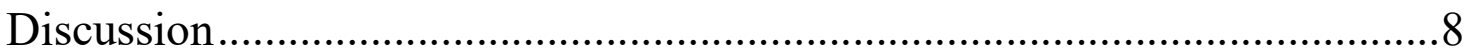

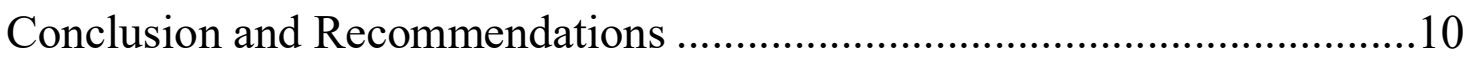

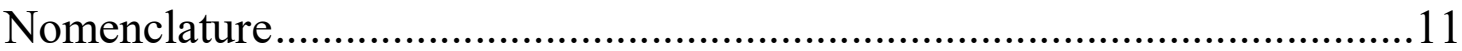

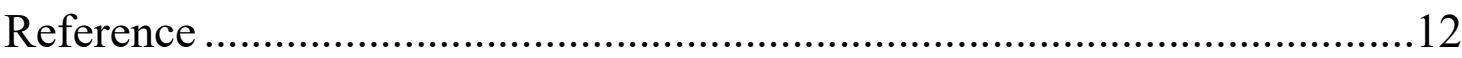

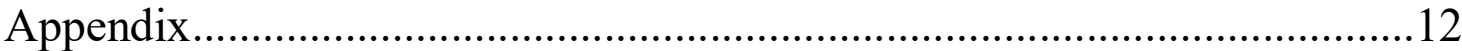




\title{
PROBLEM STATEMENT
}

\author{
As suggested by Rajan Sen
}

Structural elements such as concrete pavements used in highways or foundations of buildings are continuously supported by the underlying soil. In design it is convenient to assume that the intensity of the continuously distributed reaction at every point is proportional to the deflection at that point. This reaction can be represented as ' $k y$ ' where $k$ is referred to as the modulus of 'subgrade' reaction and $y$ the deflection.

The governing equation for the deflection in a beam is given by:

$$
E I_{Z}\left(\frac{d^{4} y}{d x^{4}}\right)=q
$$

In this equation, $E$ is the elastic modulus of the structural element, $I_{Z}$ its moment of inertia about the axis of bending, $y$ the deflection at distance $x$ under a load of intensity $q$. For an unloaded portion of a beam supported by soil, the only force acting on it is the continuously distributed soil reaction of intensity of $k y$. Thus, the governing equation for an unloaded beam on an elastic foundation is given by:

$$
E I_{Z}\left(\frac{d^{4} y}{d x^{4}}\right)=-k y
$$

The above equation may be used to determine the maximum deflection and moment under loads, e.g. a point load $P$ acting on an infinitely long beam (this corresponds for example to the load on a single railway track). 


\section{REQUIREMENT}

1. Solve Eq. (*) for the case of a point load acting on an infinitely long beam supported continuously by soil.

2. How will you use this solution to determine moments and maximum deflection for the case where there are multiple loads, e.g. two axles of a truck?

3. Apply the solution to determine the maximum deflection and maximum moment caused by the axle of a truck that consists of two concentrated 32 kip loads spaced 6 feet apart. Use $k=0,500,1000,1500$, and 2000 lbs./sq.in. .
a. What does $k=0$ mean?
b. What conclusions can you draw?
c. Where are the deflections the greatest?
d. Where are moments greatest? 


\section{MOTIVATION}

In the current design and redesign of driving surfaces like pavement, it is crucial to understand the limitations of the underlying subgrade (ground beneath the surface). Without accurate knowledge, it is not possible to assess if a subgrade can withstand the deflection of a specified load without deforming and may lead to immediate failure upon overload. Heavy vehicles are restricted from entering areas which unable to support their load. If a fully loaded eighteen wheeler were to enter an area with an unknown modulus of subgrade, the roadway could fail. Roadway failures are potentially dangerous, expensive and a cause of major traffic congestion. In today's fast paced society, this is simply unacceptable.

The primary objective for this project is to determine the moments and maximum deflection for multiple concentrated loads. Varying the values for the modulus of subgrade reaction will illustrate the deflection differences of the surface. After considering these differences, the necessary subgrade properties required for pavement design will be revealed.

\section{MATHEMATICAL DESCRIPTION AND SOLUTION APPROACH}

In the book $\underline{\text { Strength of Materials }}$, S. Timoshenko explains that the underlying equation for the deflection of a beam is:

$$
E I_{Z}\left(\frac{d^{4} y}{d x^{4}}\right)=q
$$

where $E$ is the elastic modulus of the structural element, $I_{Z}$ its moment of inertia about the axis of bending, $y$ the deflection at distance $x$ under a load of intensity $q$. Conceptually, a road may be thought as an unloaded beam of infinite length. When a vehicle drives on the road its weight 


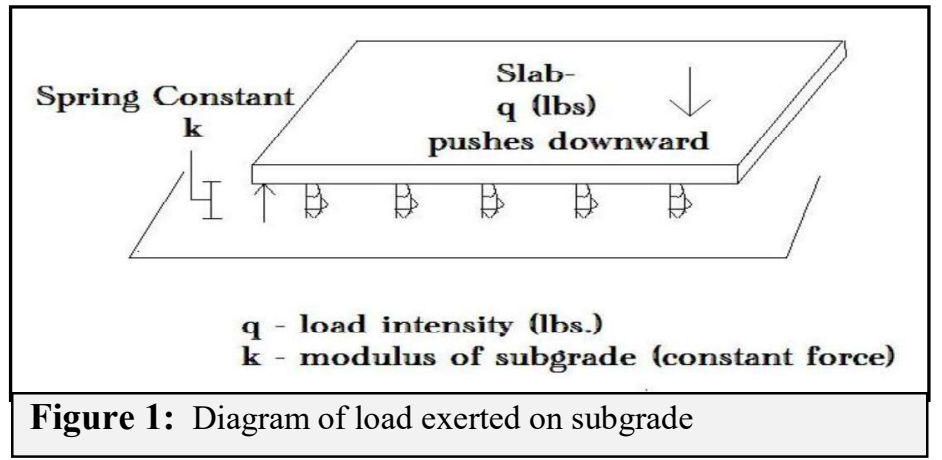

is exerted on the road and transferred to the continuous underlying subgrade. The intensity of this load can be quantified by Westergaard's modulus of subgrade reaction $k$ and the deflection $y$, i.e. $q=-k y$. The modulus of subgrade reaction may be interpreted as the pressure exerted on the subgrade and is measured in pound per squared inches. Hence, equation (1) becomes

$$
E I_{Z}\left(\frac{d^{4} y}{d x^{4}}\right)=-k y
$$

The general solution for equation (2) is represented as follows (Timoshenko, p.402):

$$
y=e^{\beta x}[A \cos (\beta x)+B \sin (\beta x)]+e^{-\beta x}[C \cos (\beta x)+D \sin (\beta x)]
$$

for some constants $A, B, C$, and $D$ and $\beta=\sqrt[4]{k /\left(4 E I_{Z}\right)}$. In this model, the road is an infinite beam supported by a subgrade so the deflection at $x=\infty$ should be zero. For $\beta>0$, as $x$ approaches infinity $e^{\beta x}$ also approaches infinity, but

$$
\lim _{x \rightarrow \infty} e^{\beta x}[A \cos (\beta x)+B \sin (\beta x)]=0
$$

so $A=B=0$. Note that at $x=0$ the beam will have a horizontal tangent. Mathematically, this means that $\left(\frac{d y}{d x}\right)_{x=0}=0$. From equation (3), this means that 


$$
\left(\frac{d y}{d x}\right)_{x=0}=\left[-e^{-\beta x}((C-D) \cos (\beta x)+(C+D) \sin (\beta x))\right]_{x=0}=-(C-D) \beta=0 .
$$

Thus, $C=D$ and (3) is simplified to

$$
y=C e^{-\beta x}[\cos (\beta x)+\sin (\beta x)] .
$$

Descriptive functions such as the deflection curve, $q$ given in (1), sheer force, $V$, and beam moments, $M$, help characterize the changes in the pavement under load. By convention, these properties are related in the following manner:

$$
q=\frac{d V}{d x}=\frac{d^{2} M}{d x^{2}}=-E I_{Z}\left(\frac{d^{4} y}{d x^{4}}\right)
$$

According to Timoshenko (p. 407) if $P$ is the force causing the deflection, the shearing force on the right side of the beam at $x=0$ is $-P / 2$ and $C$ from (4) can be computed. See that

$$
[V]_{x=0}=\left[-E I_{Z}\left(\frac{d^{3} y}{d x^{3}}\right)\right]_{x=0}=\left[-E I_{Z}\left(4 \beta^{3} C e^{-\beta x}\right)\right]_{x=0}=-4 \beta^{3} C E I_{Z}=-\frac{P}{2} .
$$

For further derivative details, see Table 1 in the Appendix. Now, $C=\frac{P}{8 \beta^{3} E I_{Z}}$ and the equation for the deflection of the pavement at $x$ under a load $P$ is

$$
y=\frac{P}{8 \beta^{3} E I_{Z}} e^{-\beta x}[\cos (\beta x)+\sin (\beta x)]=\frac{P \beta}{2 k} e^{-\beta x}[\cos (\beta x)+\sin (\beta x)],
$$

recalling that $\beta=\sqrt[4]{k /\left(4 E I_{Z}\right)}$. The sheering force and bending moments may now be calculated. For convenience, the following notation is adopted:

$$
\left\{\begin{array}{c}
\varphi(\beta x)=e^{-\beta x}(\cos \beta x+\sin \beta x) \\
\psi(\beta x)=-e^{-\beta x}(\sin \beta x-\cos \beta x) \\
\theta(\beta x)=e^{-\beta x} \cos \beta x ; \quad \zeta(\beta x)=e^{-\beta x} \sin \beta x
\end{array}\right.
$$


Using these conventions, the descriptive equations from (5) governing the pavement deflection are:

$$
\left\{\begin{array}{c}
y=\frac{P \beta}{2 k} \varphi(\beta x), \\
\frac{d y}{d x}=-\frac{P \beta^{2}}{k} \zeta(\beta x), \\
M=\frac{P}{4 \beta} \psi(\beta x), \\
V=-\frac{P}{2} \theta(\beta x) .
\end{array}\right.
$$

Since the maximum deflection and maximum bending moments occur at the origin (the point of load), they are $\delta=(y)_{x=0}=\frac{P \beta}{2 k}$ and $M_{0}=(M)_{0}=\frac{P}{4 \beta}$ respectively (Timoshenko, p.407).

\section{DISCUSSION}

In the case of multiple loads acting on an infinitely long beam, the intensities are superposed at each contact point. Since the differential equations for the underlying forces are linear, multiple forces are summed. If two 32,000 pound concentrated loads are spaced six feet

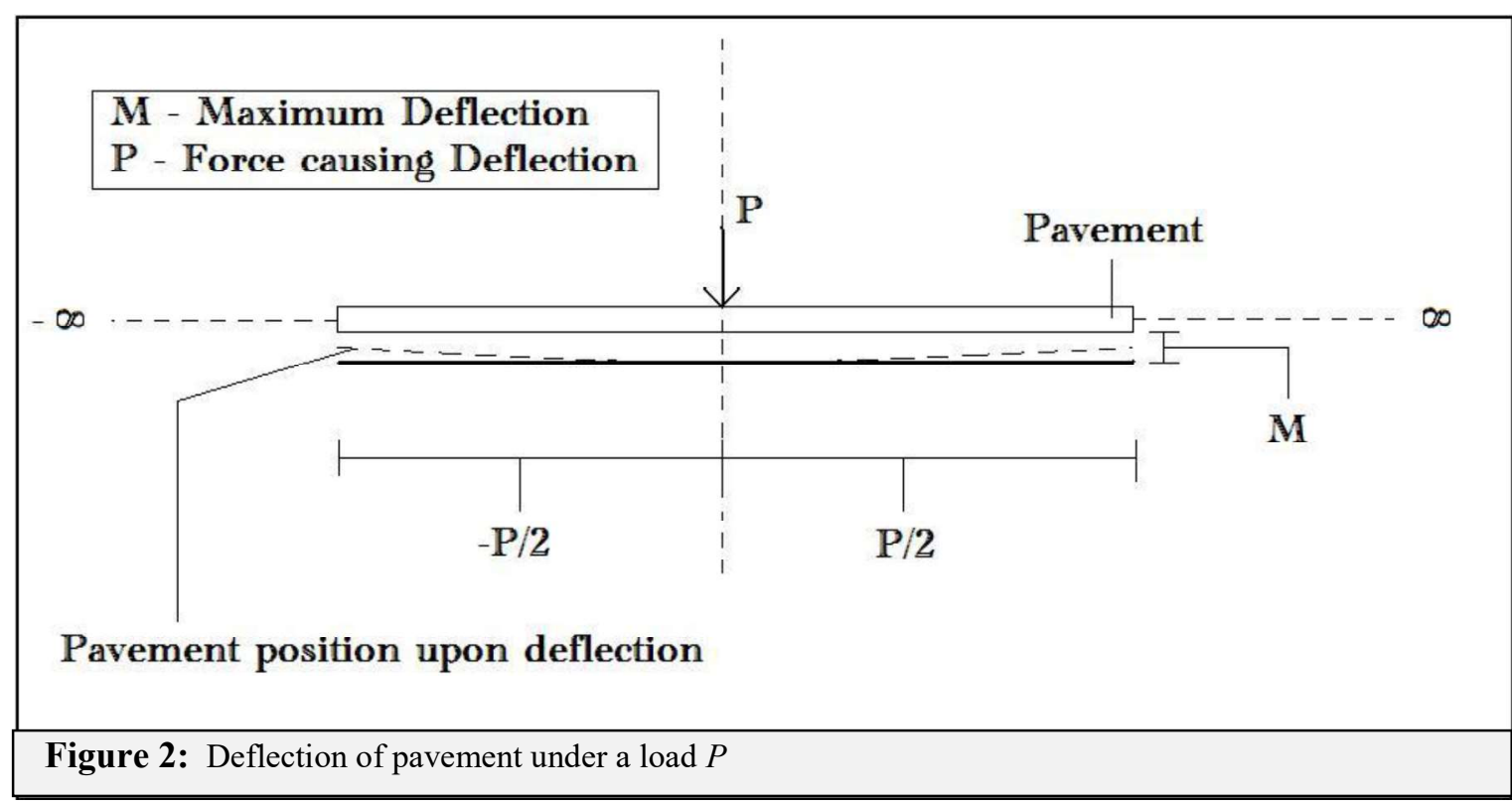


apart, multiple values of $k$ are needed to solve for the deflection in the pavement. When $k>0$ the overall modulus of subgrade reaction for two 32,000 pound loads spread six feet apart is given by the following equation (Timoshenko, p.409)

$$
k=\frac{P}{y d}
$$

where $y$ is the deflection in feet and $d$ is the distance between loads. See Table 2 in the Appendix for computed values of $k$ and $y$ for this example.

Note that $k=0$ implies that $P=0$ and no load is placed on the beam. Thus the road does not deflect and both maximum deflection and bending moments will be achieved at all points across the pavement.

For $k>0$ with multiple loads, the method of superposition says that the maximum deflections occur at

$$
\left\{\begin{array}{l}
\delta_{1}=\left(\frac{P \beta}{2 k}\right)\left(\varphi_{1}+\varphi_{2}\right), \text { under the } 1^{\text {st }} \text { axle }, \\
\delta_{2}=\left(\frac{P \beta}{2 k}\right)\left(\varphi_{1}+\varphi_{2}\right), \text { under the } 2^{\text {nd }} \text { axle }
\end{array}\right.
$$

For a 32,000 pound truck with axles 6 feet (72 inches) apart on a surface with $\beta=0.0266$, the maximum deflections

$$
\delta_{1}=\delta_{2}=\left(\frac{P \beta}{2 k}\right)(1+0.0889) \approx 1.09\left(\frac{P \beta}{2 k}\right)
$$

are $9 \%$ greater than that of a single 32,000 pound load. However, if the pavement and subgrade have a corresponding $\beta=0.0398$, then maximum deflections of the two axels will be $4 \%$ less than a single load. See Table 4 in the Appendix for further calculation details. 
Similarly the maximum bending moment may be calculated using the method of superposition and (8):

$$
M_{1}=M_{2}=\left(\frac{P}{4 \beta}\right)\left(\psi_{1}+\psi_{2}\right)
$$

From Table 5 in the Appendix, a road with $\beta=0.0266$ will have a maximum deflection of 6.1 inches and a maximum bending moment of 54,299 pounds per inch when $k=500 \mathrm{lbs} . / \mathrm{in.}^{2}$, but only a maximum deflection of 2.2 inches and a maximum bending moment of 38,395 pounds per inch when $k=2000 \mathrm{lbs} . /$ in. $^{2}$. The roughly four inch disparity in deflection may be difference between bending and cracking.

\section{CONCLUSION AND RECOMMENDATIONS}

It is important to note that a single point load acting on an infinitely long beam supported by an elastic foundation will cause the maximum deflection and bending moment to occur at the position of the point load. In the case of two concentrated loads, the equations for a single load used in conjunction with the method of superposition were used to determine the maximum deflection and bending moment. It was found that a higher value of $k$ (modulus of subgrade) will lower the maximum deflection and bending moment.

In future research, accurate values for $I_{Z}$ (moment of inertia) and $E$ (elastic modulus of the structural element) should be utilized. Inaccurate values of $I_{Z}$ and $E$ yield imprecise results. Finally, a wider range of subgrade modulus values should be examined to reach a comprehensive understanding of the deflection occurring in the structure. 


\section{NOMENCLATURE}

\begin{tabular}{|c|l|c|}
\hline Symbol & \multicolumn{1}{|c|}{ Description } & Units \\
\hline$E$ & Elastic modulus of structure & Constant \\
\hline$I_{Z}$ & $\begin{array}{l}\text { Moment of Inertia about } \\
\text { bending axis }\end{array}$ & in. \\
\hline$q$ & Load intensity & lbs. \\
\hline$x$ & Distance on horizontal plane & in. \\
\hline$y$ & Deflection at distance $x$ & in. \\
\hline$k$ & Modulus of 'subgrade' & lbs. $/$ in. ${ }^{2}$ \\
\hline$d^{4} y$ & $\begin{array}{l}\text { Fourth derivative of } y \text { with } \\
\text { respect to } x\end{array}$ & in. \\
\hline$\beta$ & $\beta=\sqrt[4]{k /\left(4 E I_{Z}\right)}$ & in. \\
\hline$P$ & Force of load & lbs. \\
\hline
\end{tabular}




\section{REFERENCE}

Timoshenko, S., Strength of Materials V.2, D Van Nostrand Company, Inc., New York, 1930.

\section{APPENDIX}

\begin{tabular}{|c|c|}
\hline \multicolumn{2}{|r|}{ Derivatives } \\
\hline$y=$ & $C e^{-\beta x}[\cos (\beta x)+\sin (\beta x)]$ \\
\hline$\frac{d y}{d x}=$ & $-2 \beta C e^{-\beta x} \sin (\beta x)$ \\
\hline$\frac{d^{2} y}{d x^{2}}=$ & $2 \beta^{2} C e^{-\beta x}[\sin (\beta x)-\cos (\beta x)]$ \\
\hline$\frac{d^{3} y}{d x^{3}}=$ & $4 \beta^{3} C e^{-\beta x} \cos (\beta x)$ \\
\hline
\end{tabular}

Table 1: Derivatives of General Solution

\begin{tabular}{|c|c|c|}
\hline \multicolumn{2}{|c|}{$k=32,000 /(y \times d)}$, & $k>0$ \\
\hline$k\left({\left.\text { lbs. } / \text { in. }^{2}\right)}^{2}\right.$ & $d($ in. $)$ & $y($ in. $)$ \\
\hline $0^{*}$ & 72 & 0 \\
\hline 500 & 72 & 0.8889 \\
\hline 1000 & 72 & 0.4444 \\
\hline 1500 & 72 & 0.2963 \\
\hline 2000 & 72 & 0.2222 \\
\hline
\end{tabular}

Table 2: Calculations in terms of $k$. 


\begin{tabular}{|c|c|c|c|c|c|c|}
\hline & \multicolumn{5}{|c|}{$\beta=\sqrt[4]{k /\left(4 E I_{Z}\right)}$} \\
\hline & & \multicolumn{5}{|c|}{$I_{Z}\left(i n .^{4}\right)$} \\
\hline & & 10 & 20 & 30 & 40 & 50 \\
\hline \multirow{5}{*}{ 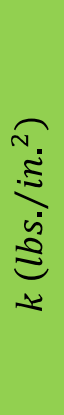 } & 0 & 0 & 0 & 0 & 0 & 0 \\
\hline & 500 & 0.0398 & 0.03344 & 0.0302 & 0.0281 & 0.0266 \\
\hline & 1000 & 0.0473 & 0.0398 & 0.0359 & 0.0334 & 0.0316 \\
\hline & 1500 & 0.0523 & 0.0440 & 0.0398 & 0.0370 & 0.0350 \\
\hline & 2000 & 0.0562 & 0.0473 & 0.4273 & 0.0398 & 0.0376 \\
\hline
\end{tabular}

Table 3: Calculation of $\beta$ using $E=5 \times 10^{6} \mathrm{psi}$

\begin{tabular}{|c|c|c|c|c|c|c|}
\cline { 2 - 7 } \multicolumn{1}{c|}{} & \multicolumn{2}{c|}{$\beta=0.0266$} & \multicolumn{2}{c|}{$\beta=0.0398$} & \multicolumn{2}{c|}{$\beta=0.0562$} \\
\hline Loads & 1 & 2 & 1 & 2 & 1 & 2 \\
\hline$\beta x$ & 0 & 1.9152 & 0 & 2.8656 & 0 & 4.0464 \\
\hline$\varphi$ & 1 & 0.0889 & 1 & -0.0393 & 1 & -0.0246 \\
\hline$\psi$ & 1 & 0.1884 & 1 & 0.0703 & 1 & -0.0029 \\
\hline
\end{tabular}

Table 4: Calculation of $\beta x, \varphi$, and $\psi$ for two wheel loads 72 inches apart

\begin{tabular}{|c|c|c|c|c|c|c|c|}
\hline & \multicolumn{2}{|c|}{$\beta=0.0266$} & \multicolumn{2}{|c|}{$\beta=0.0398$} & \multicolumn{2}{|c|}{$\beta=0.0562$} \\
\hline & & $\partial$ & $M$ & $\partial$ & $M$ & $\partial$ & $M$ \\
\hline \multirow{4}{*}{ 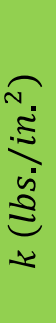 } & 500 & 6.1010 & 54299 & 4.8669 & 54086 & 4.5330 & 54926 \\
\hline & 1000 & 3.6277 & 45659 & 2.8939 & 45480 & 2.6953 & 46187 \\
\hline & 1500 & 2.6765 & 41258 & 2.1351 & 41096 & 1.9886 & 41735 \\
\hline & 2000 & 2.1570 & 38395 & 1.7207 & 38244 & 1.6027 & 38839 \\
\hline
\end{tabular}

Table 5: $\partial$ - Maximum Deflection (in.) and

$M$ - Maximum Bending Moment (lbs./in.) 